\title{
Análise do desastre hidrometeorológico ocorrido em dezembro de 2018 na cidade de Jacobina - BA.
}

\author{
Analysis of the hydrometerological disaster occurred december 2018 \\ in Jacobina - BA.
}

Marcos Paulo Souza Novais

\section{RESUMO}

Neste trabalho foi analisado o desastre hidrometeorológico ocorrido em dezembro de 2018, na cidade de Jacobina. Esse estudo objetivou compreender o desastres, através da identificação e descrição das condições de contorno dos eventos deflagradores, a partir da compreensão atuação dos sistemas atmosféricos, dos dados de precipitação e observação da paisagem urbana e das intervenções antrópicas nos sistema de hidrográfico da cidade, além de apresentar os danos e prejuízos resultante, que culminou em declaração de Situação de Emergência (SE) por parte do município. Área de estudo localiza-se na sub-bacia do rio Itapicuru-Mirim, que integra a Bacia Hidrográfica do Itapicuru, região Centro-Norte do estado da Bahia. O percurso metodológico consistiu de 4 (quatro) etapas: 1) Revisão bibliográfica, pesquisa documental e coleta de dados secundários; 2) Coleta de dados de precipitação diária das estações pluviométricas localizadas no perímetro urbano e tratamento estatístico; 3) Coleta e interpretação de imagens de satélite meteorológico e cartas sinóticas; 4) Levantamento de informações sobre danos e prejuízos no Formulário de Informação do Desastre, site e blogs regionais. Os resultados apontam que os sistemas atmosféricos atuantes no mês de dezembro no Nordeste do país, especialmente na região Centro-Norte da Bahia estiveram associadas à Zona de Convergência do Atlântico - ZCAS, cavados de médios e altos níveis e Vórtice Ciclone de Alto Nível - VCAN. A análise dos dados de precipitação apontou o dia 09/12/2018 como o dia de máxima diária (24h) com 82,2 mm. Foi possível observar que a geomorfologia da paisagem urbana e as intervenções antrópicas nos rios da cidade de Jacobina, quando associados a chuvas intensas, resultam em enxurradas e alagamentos, afetando principalmente a população vulnerável e que ocuparam áreas suscetíveis aos riscos, provocando diversos danos e prejuízos. A partir deste estudo, é possível concluir que os desastres ocorridos em Jacobina são resultados de condicionantes naturais e sociais, em função da geomorfologia da paisagem urbana, das intervenções antrópicas nos rios que drenam a cidade e na vulnerabilidade e suscetibilidade da população que ocupam as áreas afetadas.

Palavras-chave: Desastres; Eventos Hidrometereológicos; Geomorfologia 


\section{ABSTRACT}

This paper analyzes the hydrometeorological disaster that occurred in December 2018 in the city of Jacobina. This study aimed to understand the disasters, through the identification and description of the boundary conditions of the triggering events, from the understanding of the atmospheric systems performance, the precipitation data and observation of the urban landscape and the anthropic interventions in the city's hydrographic system. to present the resulting damages, which culminated in a declaration of Emergency Situation (SE) by the municipality. Study area is located in the ItapicuruMirim River sub-basin, which is part of the Itapicuru River Basin, in the Center-North region of the state of Bahia. The methodological course consisted of 4 (four) steps: 1) Bibliographic review, documentary research and secondary data collection; 2) Collection of daily rainfall data from rainfall stations located in the urban perimeter and statistical treatment; 3) Collection and interpretation of meteorological satellite images and synoptic charts; 4) Gathering information about damage and loss on the Disaster Information Form, regional website and blogs. The results indicate that the atmospheric systems operating in December in the Northeast of the country, especially in the Central North region of Bahia were associated with the Atlantic Convergence Zone - ZCAS, medium and high level troughs and High Level Cyclone Vortex - VCAN. The analysis of the precipitation data indicated the day 09/12/2018 as the maximum daily day (24h) with $82.2 \mathrm{~mm}$. It was observed that the geomorphology of the urban landscape and anthropogenic interventions in the rivers of the city of Jacobina, when associated with heavy rains, result in flooding and flooding, mainly affecting the vulnerable population and occupying areas susceptible to risks, causing various damages. . From this study, it is possible to conclude that the disasters that occurred in Jacobina are the result of natural and social constraints, due to the geomorphology of the urban landscape, the anthropic interventions in the rivers that drain the city and the vulnerability and susceptibility of the population occupying the areas. Affected

Keywords:_Disasters; Hydrometeological Events; Geomorphology

\section{INTRODUÇÃO}

É inquestionável a relevância e a influência da água na saúde, na organização do território, da sociedade, ou seja, na vida humana em sua plenitude. A água é um mineral essencial à vida. Em determinadas situações e contextos, a água tanto pode provocar problemas e conflitos, podendo colocar em risco a sobrevivência, como também pode ser instrumento de esperança, de manutenção da vida. O mau tempo para uns, pode representar bom tempo para outros, pois a água pode ser riqueza, como pode ser tristeza.

Neste trabalho, o destaque foi para os desastres hidrológicos que possuem entre suas causas a ação dos processos naturais que envolvem excesso de água no sistema afetado, normalmente relacionados aos extremos de precipitação e cheia e deficiência no sistema de drenagem urbana, atingido principalmente a população que 
ocupam áreas sensíveis a drenagem e com restrições de uso e ocupação (planícies inundação, margens de rios, córregos, lagoas, reservatórios artificiais e nascentes), e socialmente vulnerável. Estima-se que $50 \%$ da população do planeta vivam em menos de 0,4\% da superfície terrestre (Benntt; Doyle, 1997). Muitos desses lugares são perigosos ou são propensos a riscos de desastres, e é justamente onde foram construídas a maioria das cidades (Cardona, 2008).

Entre 1995 e 2015 os desastres afetaram 51 milhões de pessoas no Brasil (Centre for Research on the Epidemiology of Disasters - CRED e United Nations Office for Disaster Risk Reduction - UNISDR, 2016) e custaram pelo menos 182,8 bilhões de reais de prejuízos (BANCO MUNDIAL, 2012). Estudos recentes de avaliação de perdas e danos, estimaram que os impactos econômicos das enchentes/inundações e deslizamentos em Santa Catarina, Pernambuco, Alagoas e Rio de Janeiro, no período de 2008-2011 foram da ordem de $\mathrm{R} \$ 15,5$ bilhões (Marengo, 2015).

Diante deste contexto, eventos de ordem natural, como o extravasamento das águas de um rio e a inundação de sua planície fluvial, quando associado a ocupações do espaço (lugar) por uma população vulnerável, pode resultar em desastres, muitas vezes de grande proporção. Blaikie et. al (1996) dizem que os desastres são uma mistura complexa de ameaças naturais e ações humanas. Assim, a urbanização e a densidade populacional associado aos extremos do tempo e clima, como apontados pelos relatórios do Painel Intergovernamental de Mudanças Climáticas, na sigla em inglês - (IPCC) de 2012, 2013, 2014 e apud (Marengo, 2015) e intensificados pelo aumento da vulnerabilidade social, principalmente em países emergentes, tem resultado no aumento da frequência e intensidade dos desastres. Segundo OliverSmith et al. (1999) os desastres, seja eles de grande, médio e pequeno porte estão se tornando mais frequentes e resultando em vultosos danos e prejuízos, que aumentam a cada desastre.

A legislação brasileira a partir do Glossário da Defesa Civil Nacional (Castro, 1998), define desastre como sendo o resultado de eventos adversos, naturais ou 
provocados pelo homem, sobre um ecossistema (vulnerável), causando danos humanos, materiais e/ou ambientais e consequentes prejuízos econômicos e sociais.

No contexto desta pesquisa, uma categoria particular de desastres foi abordada, os desastres hidrológicos. Segundo autores como Kobiyama et al., (2006); Miguez et al., (2018) possuem entre suas causas a ação de processos naturais e sociais, relacionados ao excesso de água, devido aos extremos de cheias e ocupações de áreas suscetíveis, intervenções e construções antrópicas.

Neste sentido, termos como "enchente e/ou cheia" e "inundações" bruscas(enxurradas) ou graduais, precisam ser evocados e discutidos, tendo em vista possíveis confusões que persistem no uso cotidiano e no meio técnico, tendo em vista há relação entre estes termos, mas que, de fato, eles não são iguais. Neste trabalho se faz o uso das definições presentes no Atlas Brasileiro de Desastres Naturais (CEPED/UFSC, 2013) e de autores como Tucci (2005); Goerl e Kobyama (2005) e Miguez et al., (2018).

Inicialmente, as palavras "enchente" ou "cheia", têm como origem o verbo encher, do latim implere, que significa "ocupar o vão, a capacidade ou a superfície", "tornar cheio ou repleto". Portanto, é correto dizer que ocorreu uma enchente ou cheia quando as águas de um pequeno rio (córrego, riacho, arroio e/ou ribeirão) ou de grande dimensão, apresenta elevação do nível de água, acima de sua vazão normal, porém sem transbordar. Não há rio em que no período de ocorrência das maiores precipitações não ocorra enchente ou cheia (Santos, 2007, Tucci, 2014; Miguez et al., 2018).

Quando a vazão atinge seu nível máximo, e ocorre seu transbordamento para as áreas marginais (planície de inundação) ocorre a inundação. (Santos, 2007; BRASIL.MINISTÉRIO DAS CIDADES/INSTITUTO DE PESQUISAS TECNOLÓGICAS MC/IPT, 2007; Miguez et.al., 2018), A Figura 1, ilustra a diferença entre a enchente e uma situação de inundação. 
Figura 1- Esquema representativo da enchente e inundação

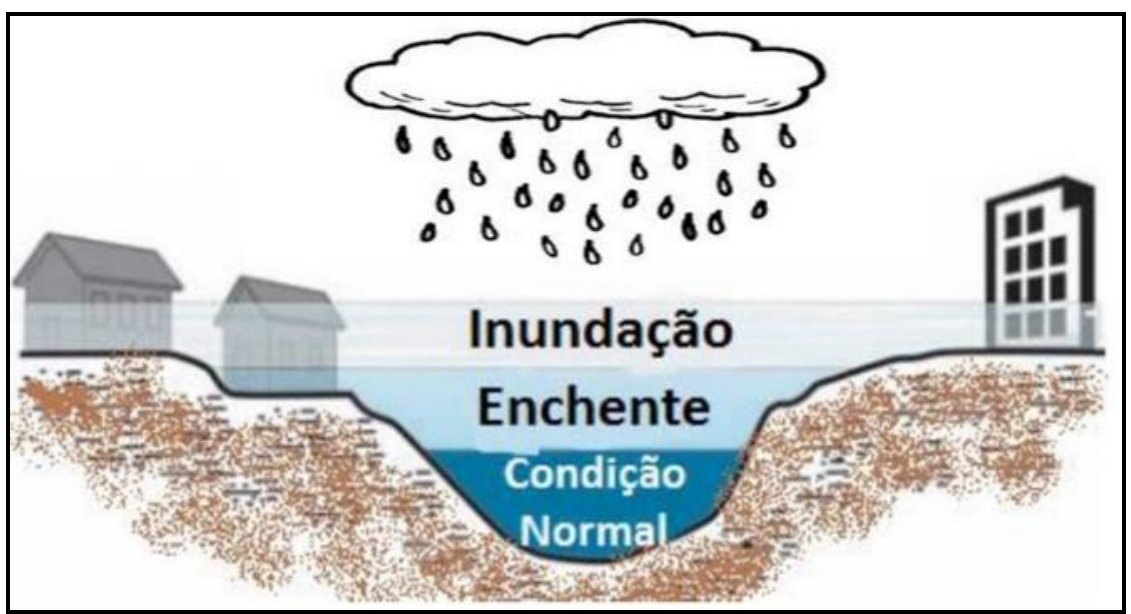

Fonte: MC/IPT - São Paulo, 2007

As inundações podem ocorrer de duas formas: brusca ou progressivamente (gradual). A inundação brusca está atrelada a subida rápida da altura da água no leito normal, onde em curto intervalo de tempo transborda e cobre áreas da planície fluvial e de inundação, muitas vezes sendo resultado de precipitações intensas.

Já as inundações progressivas ou graduais, que estão relacionadas com os trechos mais planos dos rios, e ocorrem devido ao transbordamento mais lento, resultado de precipitações prolongadas que, por não serem concentradas no tempo, fazem subir a cota da água no leito de forma lenta, e nem sempre estão associadas às precipitações na área da ocorrência do fenômeno, mas a eventos de precipitação extrema à montante, como algumas inundações fluviais nas áreas de foz das bacias de drenagem (Tucci, 2014).

Grande parte dos desastres no território brasileiro, estão associados à falta ou excesso de água. Dados do The International Disasters Database - EM-DAT (2009), observados entre 1999 - 2008, apontam que - 68\% dos desastres - foram deflagrados por enchentes, inundações (bruscas/graduais) e alagamentos e 8,4\% corresponderam a secas e estiagens.

Na Bahia, os desastres ocorridos no período de 1991 - 2016, somam 3.605 registros oficiais, sendo que $79 \%$ se refere a eventos de estiagem e seca, $17 \%$ a enxurradas e inundações e 2\% a alagamentos (CEPED/UFSC, 2013; Novais, 2018). A 
fragilidade e suscetibilidade ambiental aos desastres afetam grande extensão territorial da Bahia, produzindo efeitos negativos e prolongados na economia e na sociedade (CEPED/UFSC, 2013).

No âmbito da bacia hidrográfica do Rio Itapicuru, os desastres no período de 1991 - 2016, somam 725 registros, sendo que 87,7 \% se refere a estiagem e seca, 9,7\% a enxurradas e inundações e 1,9\% a alagamentos (CEPED/UFSC, 2013; Novais, 2018). Dos 667 desastres relacionados ao excesso de água na Bahia, 84 ocorreram na bacia do Itapicuru, isso representa 12,6\% dos eventos, portanto, valor considerável, quando se trata de uma bacia hidrográfica com $80 \%$ do seu território no semiárido e ter parte do considerável de municípios no Polígono das Secas, aos quais na maior parte do ano sofre com a escassez hídrica.

Neste contexto, o estudo objetivou compreender o desastre ocorrido em dezembro de 2018 em Jacobina, a partir da identificação e descrição das condições de contorno que estiveram associadas aos eventos hidrometeorológico e das características da paisagem urbana e intervenções antrópicas, que culminou em impacto junto a população vulnerável, reconhecida pelo poder público através da declaração de Situação de Emergência (SE).

O trabalho teve como pressuposto a análise de variáveis físicas (precipitação e sistemas atmosféricos), características naturais da paisagem e apresentação dos danos e prejuízos gerados pelo evento.

\section{MÉTODO E METODOLOGIA}

O presente estudo consiste em uma análise do desastre hidrológico, resultante de evento extremo de precipitação ocorrido em dezembro de 2018 na sede urbana do município de Jacobina, situada na região Centro Norte da Bahia, pertencente a Bacia do Hidrográfica do Rio Itapicuru, a partir de uma abordagem integrada no estudo de desastres. 
O município de Jacobina (localizado entre as coordenadas geográficas de $11^{\circ}$ $10^{\prime}$ de latitude Sul e $40^{\circ} 30^{\prime}$ de longitude Oeste), (Figura 2), no Piemonte da Chapada Diamantina-BA, dista de Salvador aproximadamente $330 \mathrm{~km}$, possui uma área de 2.360 quilômetros quadrados e se encontra a uma altitude média de $485 \mathrm{~m}$ acima do nível do mar (Pinheiro, 2004; IBGE, 2010). Sua sede urbana é assentada às margens do às margens do rio Itapicuru-Mirim e do seu afluente rio do Ouro. A urbanização em Jacobina teve seu início a partir do século XVII, com a descoberta de riquezas minerais em seu espaço natural, onde deu-se com a ocupação de encostas e vales, sendo a água (rios) e o ouro fatores decisivos na constituição do espaço urbano.

Figura 2 - Localização da área do município de Jacobina - BA



De acordo com os dados do último Censo Demográfico (IBGE, 2010), o município de Jacobina apresenta uma população de 79.247 habitantes, sendo que deste total, 55.868 corresponde à população urbana e 23.379, à população rural, densidade 
demográfica de 33, 58 hab/km². Atualmente a população do município de Jacobina é estimada em 80.394 habitantes (IBGE, 2018).

Na região podem ser distinguidas importantes unidades geológicas como: os Complexos Caraíba, Itapicuru, Saúde, Mairi e Ipirá; os Grupos Chapada Diamantina (Formações Tombador e Caboclo), Una (Formações Bebedouro e Salitre) e Jacobina (Formações Rio do Ouro e Serra do Córrego), além de coberturas detríticas e depósitos terciário-quaternários (Pinheiro, 2004).

César e Alves (2001), de forma simplificada, afirmam que Jacobina está sobre dois tipos principais de relevo:

- O Serrano - formado pela estrutura meta-sedimentar da Serra de Jacobina no sentido norte-sul, caracterizada pelos espigões paralelos e intercalados entre as altitudes de 950 e $1250 \mathrm{~m}$.

- O Planalto ondulado - com altitudes médias em torno de $450 \mathrm{~m}$, é formado por pequenos morros, que participam do complexo entre a Serra de Jacobina e a Serra do Tombador.

O clima regional, segundo a classificação de Köppen é do tipo AW - ou seja, quente, caracterizado por duas estações definidas (inverno e verão). Localmente, o clima do município, varia entre seco sub-úmido e semi-árido, sofrendo forte influência da topografia, com precipitação média em torno de $863 \mathrm{~mm}$ concentrada nos meses de janeiro a março (Pinheiro, 2004).

Quanto à cobertura vegetal, observa-se que grande parte do município é recoberta por áreas já antropizadas, de vegetação secundária com palmeiras, bem como, áreas utilizadas, principalmente na pecuária com pastagens e na agricultura. A vegetação nativa restante é composta pelos refúgios ecológico-montanos, as áreas de tensão ecológica (áreas transicionais), as florestas estacionais deciduais e semideciduais e a caatinga arbórea e arbustiva (Pinheiro, 2004).

As condições de relevo, clima e vegetação permitem o desenvolvimento de solos que variam entre latossolos, podzólicos, planossolos, cambissolos e litólicos, que 
também se apresentam bastante alterados pelas atividades de agricultura e pastagem (Pinheiro, 2004).

Figura 3 - Fluxograma das atividades desenvolvidas no estudo

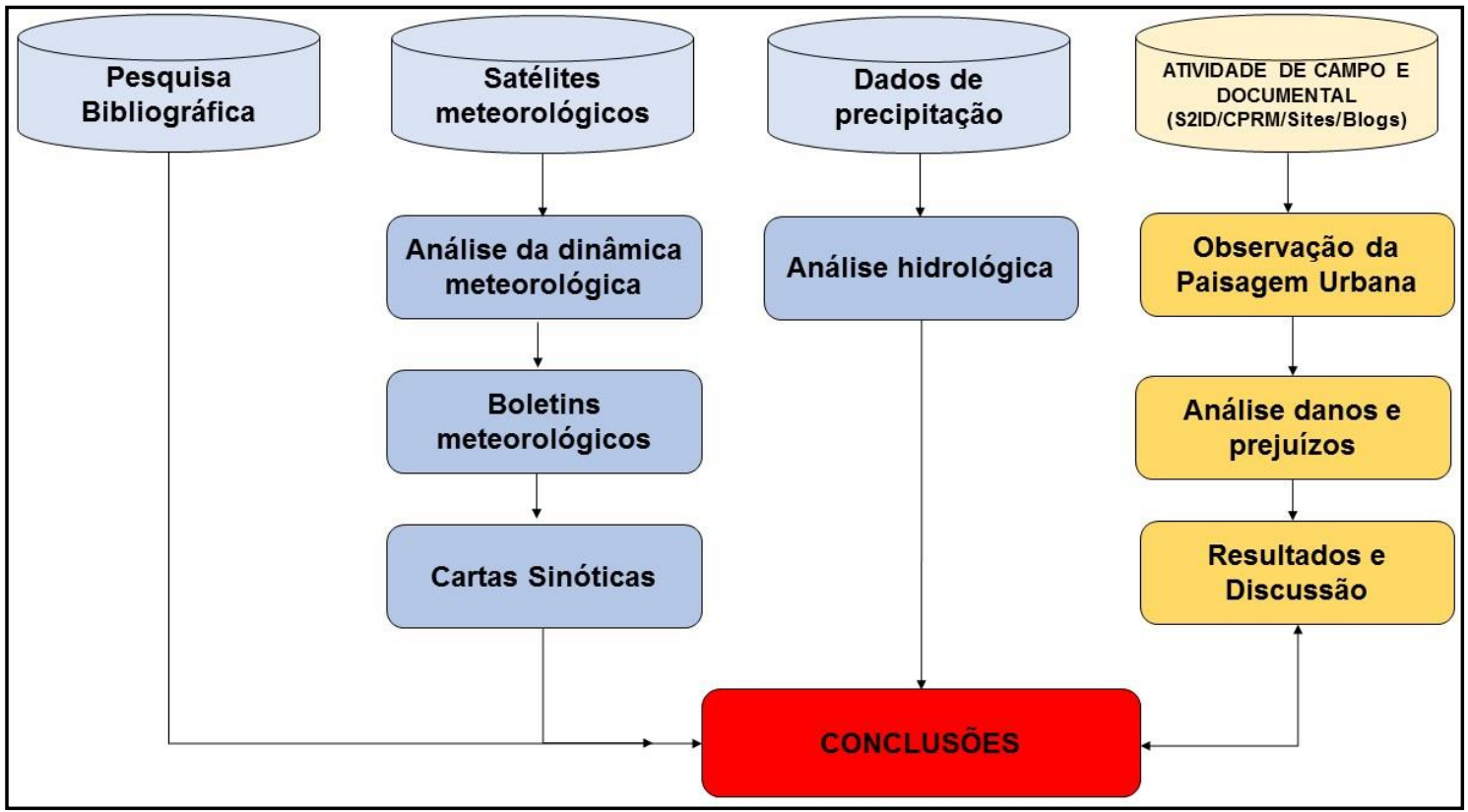

Fonte: do autor (2019)

No tocante ao percurso metodológico, consiste de 4 (quatro) etapas conforme fluxograma (Figura 3) : 1) Revisão bibliográfica, pesquisa documental e coleta de dados secundários; 2) Coleta e interpretação de imagens de satélite meteorológico, boletins meteorológicos e cartas sinóticas; 3) Coleta de dados de precipitação diária das estações pluviométricas localizadas no perímetro urbano e análise hidrológica; 4) Levantamento de informações sobre, áreas de risco, danos e prejuízos junto ao Sistema Integrado de Informações de Desastres, vinculado a Secretaria Nacional de Proteção e Defesa Civil, através de consulta ao Formulário de Informações de Desastres - FIDE, ao Serviço Geológico do Brasil (SGB-CPRM), sites e blogs regionais.

A primeira etapa compreende levantamento bibliográfico sobre os seguintes conceitos: desastres, desastres hidrológicos: inundações bruscas (enxurradas).

Para a análise detalhada dos mecanismos e dinâmica atmosférica associada à precipitação intensa ocorrida nesse evento hidrometeorológico, primeiramente foram 
analisados os boletins meteorológicos do Centro de Previsão de Tempo e Estudos Climáticos do Instituto Nacional de Pesquisas Espaciais (CPTEC-INPE). Além disso, foram compiladas as imagens do satélite meteorológico METEOSAT Colorida, obtidas junto à Divisão de Satélites e Sistema Ambientais (DAS-INPE) associado as cartas sinóticas distribuídas pelo CPTEC/INPE, para interpretação da dinâmica atmosférica em um contexto mais continental, possibilitando compreender a gênese dos sistemas atuante na região Nordeste.

A etapa seguinte abrange a coleta e análise dos dados disponíveis de precipitação, provenientes de 4 (quatro) estações pluviométricas no limite da sede urbana de Jacobina, de responsabilidade do órgão ambiental estadual Instituto do Meio Ambiente e Recursos Hídricos - INEMA e disponibilizadas através do Sistema Estadual de Informações Ambientais e de Recursos Hídricos - SEIA, utilizados para obter a média da precipitação diária (24h), a média do acumulado mensal e a precipitação máxima e seu intervalo de ocorrência. Os resultados foram sintetizados e organizados em tabelas e gráficos visando facilitar a visualização, análise e discussão dos resultados. O uso integrado das informações, permitiu inferir sobre o sistema atmosférico atuante sobre o estado da Bahia, com destaque para o município de Jacobina, bem como auxiliar na caracterização das condições de contorno da precipitação nos contextos temporal e espacial.

A quarta etapa do estudo reside em pesquisa documental e levantamento de dados no Formulário de Informações de Desastres - FIDE encaminhado para Superintendência de Defesa Civil Estadual (SUDEC) e Secretaria Nacional de Proteção e Defesa Civil e atividade de campo afim de observar a configuração geomorfológica e as intervenções antrópicas na paisagem urbana e sua possível contribuição para ocorrência do desastre. Além disso, realizou-se representação espacial das Áreas em Alto e Muito Alto Risco a Enchentes, Inundações e Movimentos de Massa a partir dos dados disponibilizados pelo Serviço Geológico do Brasil (CPRM, 2014). 
A junção das informações e dados permite fazer uma análise integrada do evento hidrometeorológico que afetou a sede urbana de Jacobina, e que tendo em vista as condições de vulnerabilidade da população resultou em um desastre.

\section{RESULTADOS E DISCUSSÕES}

O mês de dezembro de 2018 iniciou com as chuvas de verão em Jacobina. Nos 10 (dez) primeiros dias do mês foram $181 \mathrm{~mm}$ de chuva, registrado na estação Jacobina (Felix Tomaz) - (cód. 291750802A). Para caracterizar estes os sistemas atmosféricos atuantes e que esteve associado ao desastre que afetou a cidade, foram utilizadas as cartas sinóticas pré e pós eventos de chuvas intensas.

Nas Figura 4 e 5 é apresentada uma sequência de Cartas Sinóticas de Superfície (CPTEC/INPE) e imagem colorida METEOSAT (CPTEC/INPE) e juntamente com os Boletins Meteorológicos, pode-se constatar que as chuvas de dezembro foram resultado da formação e atuação de uma Zona de Convergência do Atlântico Sul (ZCAS), que se manteve sobre o estado da Bahia por mais de 10 (dias), deixando o tempo instável e provocando acumulados expressivos de precipitação. Segundo Carvalho e Jones (2009) a ZCAS é caracterizado por corredor de nebulosidade e chuvas com orientação noroeste-sudeste, que se estende desde a Amazônia até o Sudeste do Brasil, e com certa frequência sobre o oceano Atlântico Subtropical, atuando principalmente nos meses de verão.

Entre os dias (07, 08 e 09/12), o avanço do sistema frontal em superfície, sobre o Atlântico e do cavado em níveis médios e altos, com eixo entre o interior do Brasil e o Atlântico, reorganizaram e deram suporte para a manutenção da Zona de Convergência do Atlântico Sul (ZCAS) e com a presença do Vórtice Ciclônico em Altos Níveis (VCAN) manteve o tempo instável em grande parte do Nordeste do Brasil, com a ocorrência de pancadas de chuva de forma isolada e fortes em algumas localidades. A ZCAS começou a se desfigurar a partir do dia 10/12. 
Figura 4 - Cartas Sinóticas de Superfície, 01 a 10/12/2018

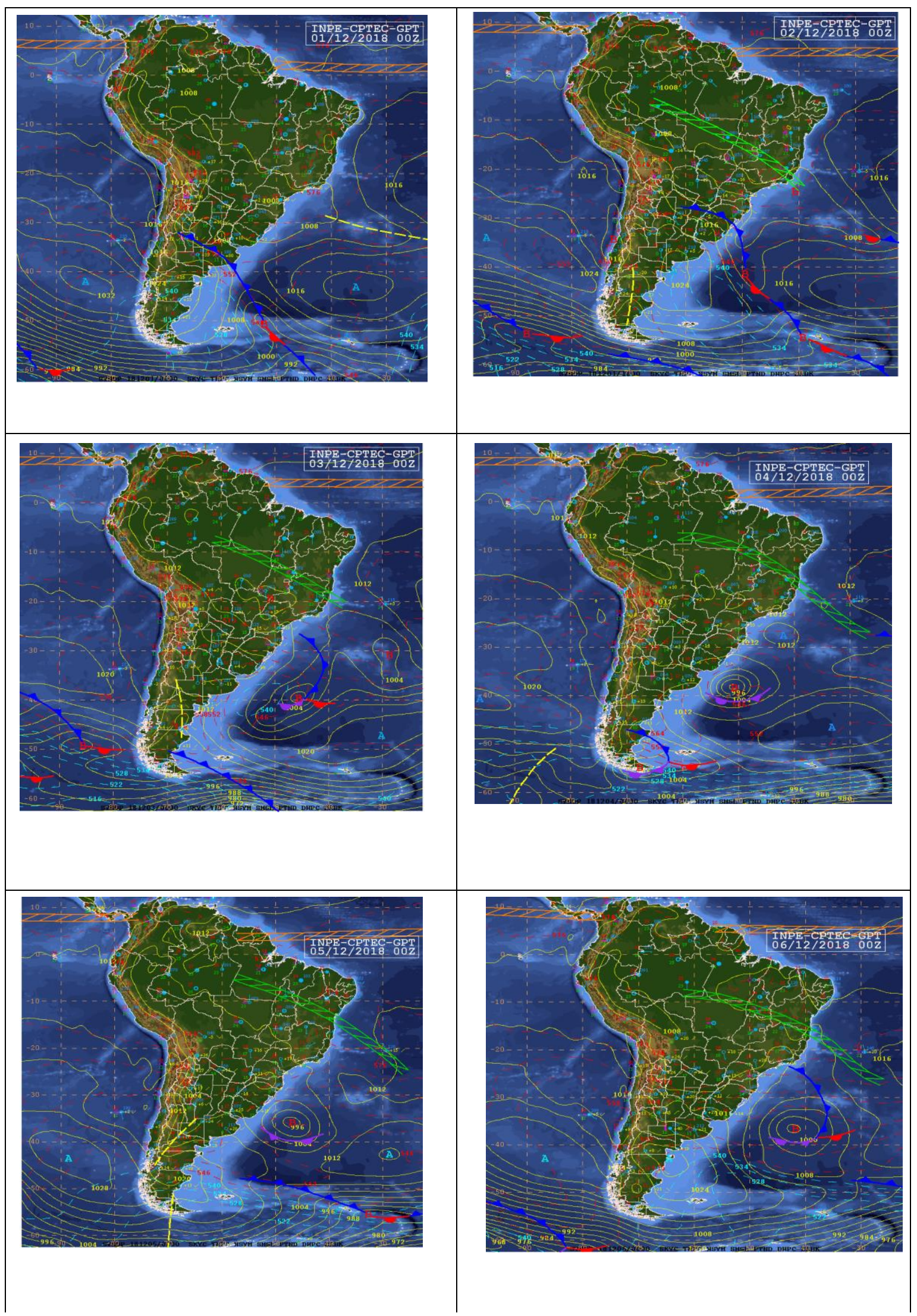

Continua... 
Figura 4 - conclusão

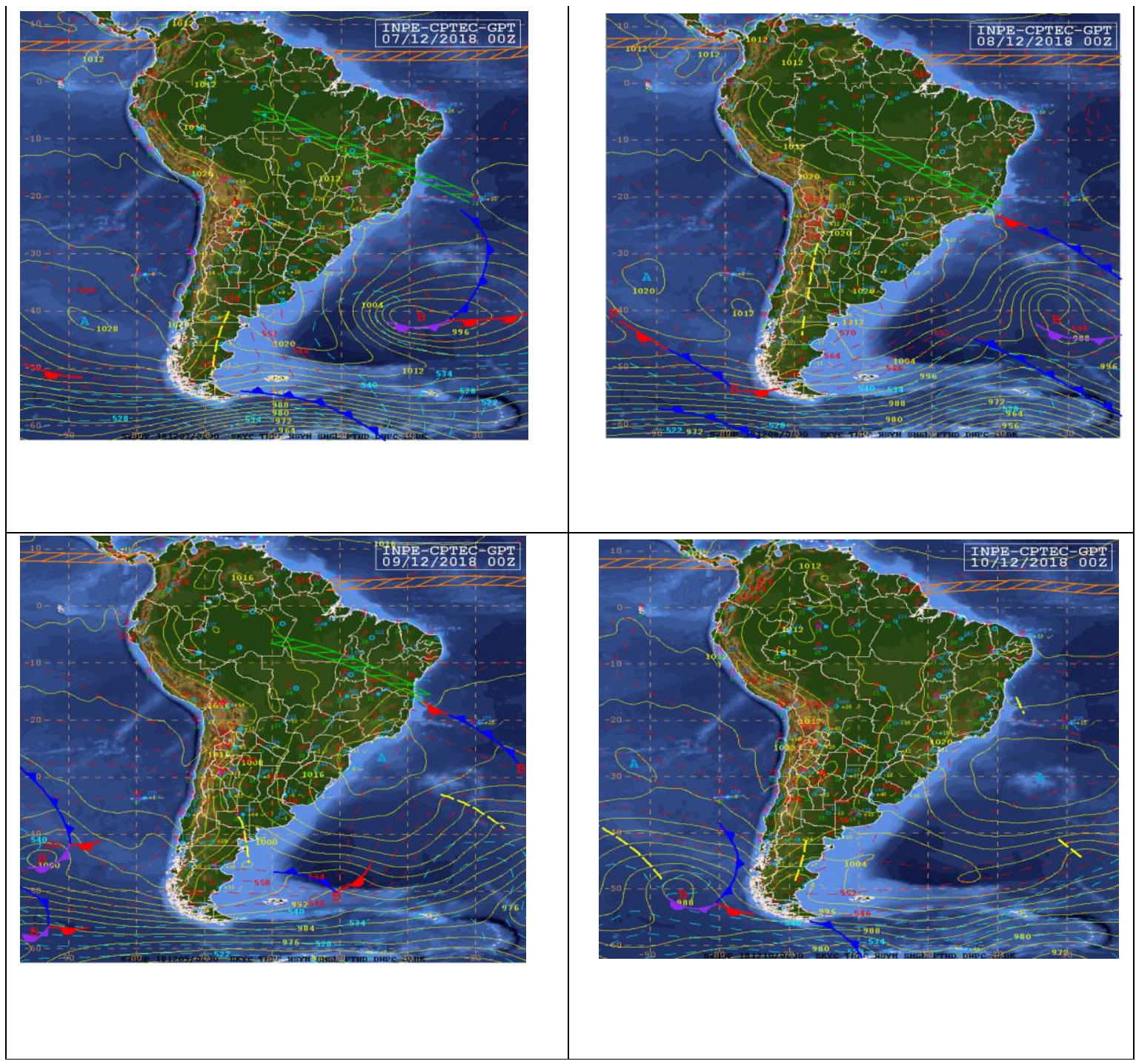

Fonte: CPTEC/INPE, 2018

Ao analisar de forma detalhada os dados de precipitação (chuvas) a partir do acumulado mensal e acumulado máximo de chuva diária (24 horas) registrado no mês dezembro de 2018 na cidade de Jacobina, em 4 (quatro) estações pluviométricos/meteorológicas localizadas no perímetro urbano, de responsabilidade do Instituto Nacional de Meteorologia - INMET e do Instituto de Meio Ambiente e Recursos Hídricos - INEMA do estado. Observou-se que a média do acumulado mensal das 4 (quatro) estações foi de 154,3 mm, superior em 36,6\% a média climatológica de Jacobina para o mês de dezembro, que é de 112,9 mm (INMET, 1991), Tabela 1. 
Figura 5 - Imagens satélite METEOSAT dos 08 e 09/12/2018, em destaque o corredor de nebulosidade formado pela ZCAS

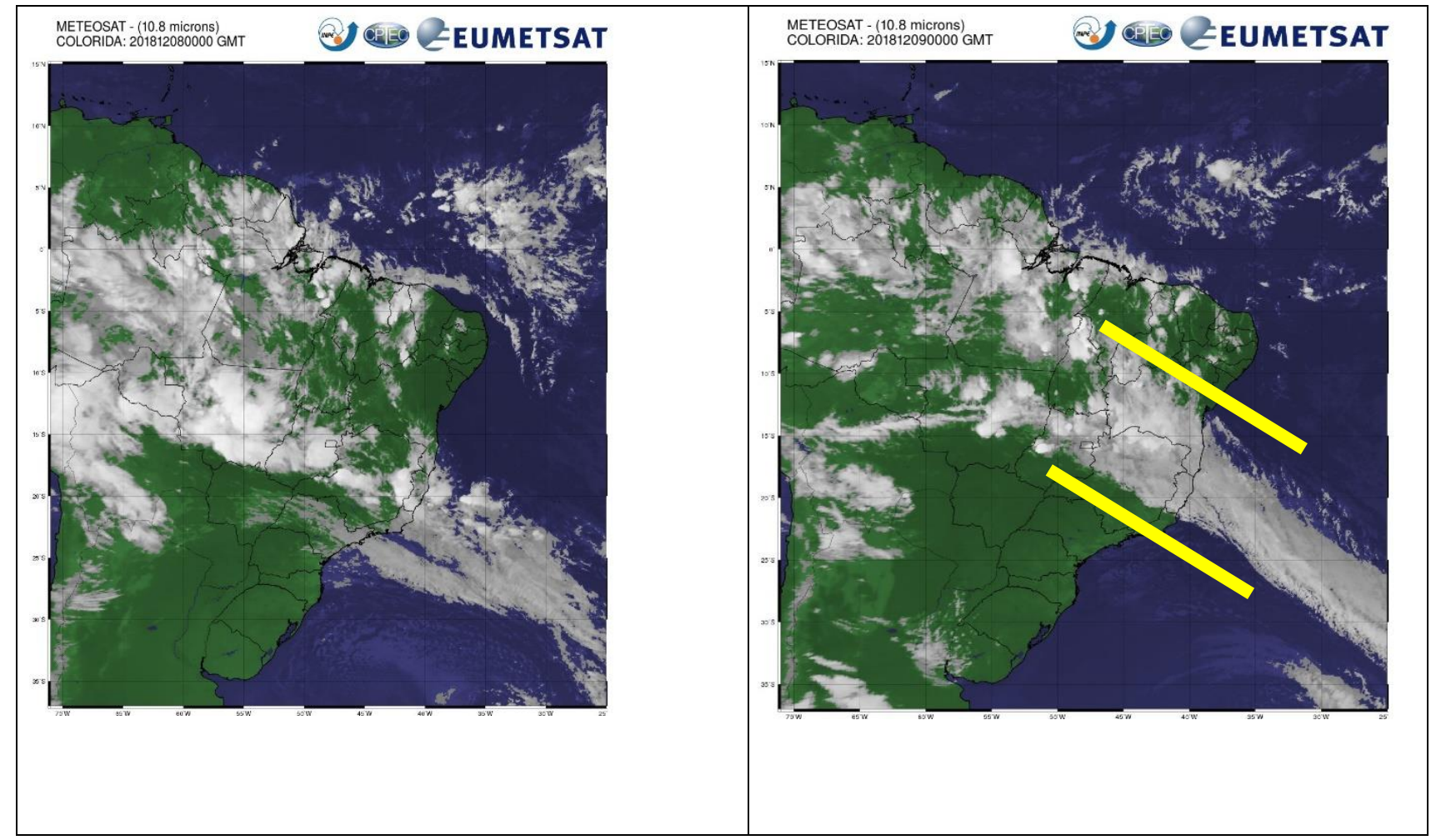

Fonte: CPTEC/INPE, 2018

Tabela 1 - Precipitação acumulada de dezembro de 2018, na área urbana de Jacobina - BA

\begin{tabular}{|c|c|c|c|c|}
\hline $\begin{array}{l}\text { Estação/ } \\
\text { Código }\end{array}$ & Localização & $\begin{array}{c}\text { Acumulado } \\
\text { Mensal }\end{array}$ & $\begin{array}{l}\text { Acumulado } \\
\text { Diário (24h) }\end{array}$ & Dia Máxima \\
\hline Jacobina - A440 & $\begin{array}{l}\text { Latitude - } 11205136 / \\
\text { Longitude - } 40464979\end{array}$ & 158,2 & 56,4 & 9 \\
\hline Jacobina - 83186 & $\begin{array}{l}\text { Latitude - } 11172778 \text { / } \\
\text { Longitude - } 40534167 \\
\end{array}$ & 162,7 & 67,8 & 9 \\
\hline $\begin{array}{l}\text { Jacobina (Felix } \\
\text { Tomaz) - } \\
\text { 291750802A }\end{array}$ & $\begin{array}{l}\text { Latitude - } 11174316 \text { / } \\
\text { Longitude - } 40517837\end{array}$ & 182,0 & 82,2 & 9 \\
\hline $\begin{array}{l}\text { Jacobina (Ladeira } \\
\text { Vermelha) - } \\
291750802 \mathrm{~A} \text { - }\end{array}$ & $\begin{array}{l}\text { Latitude - } 11161707 \text { / } \\
\text { Longitude - } 40554213\end{array}$ & 114,4 & 32,6 & 10 \\
\hline $\begin{array}{l}\text { Média } \\
\text { Acumulado } \\
\text { Mensal }\end{array}$ & & 154,3 & & \\
\hline
\end{tabular}

Fonte: INMET (2018); INEMA (2018). Elaborado pelo autor 
Verificou-se também que os maiores acumulados diários (24h) de 82,2 mm e 67,8 mm respectivamente, registrado nas estações Felix Tomaz (291750802A) e Jacobina (83186) ocorreram no dia 09/12/2018, sendo a média do acumulado diário (24h) do 09/12/18 de 68,8 mm.

Figura 6 - a); Ocupação em vertente com declividade intensa, próxima canal de drenagem b) Retificação e estreitamento da calha do rio Itapicuru-Mirim; c) Deficiência do sistema de drenagem urbana e, d) Danos na pavimentação das ruas, após evento intenso de chuva

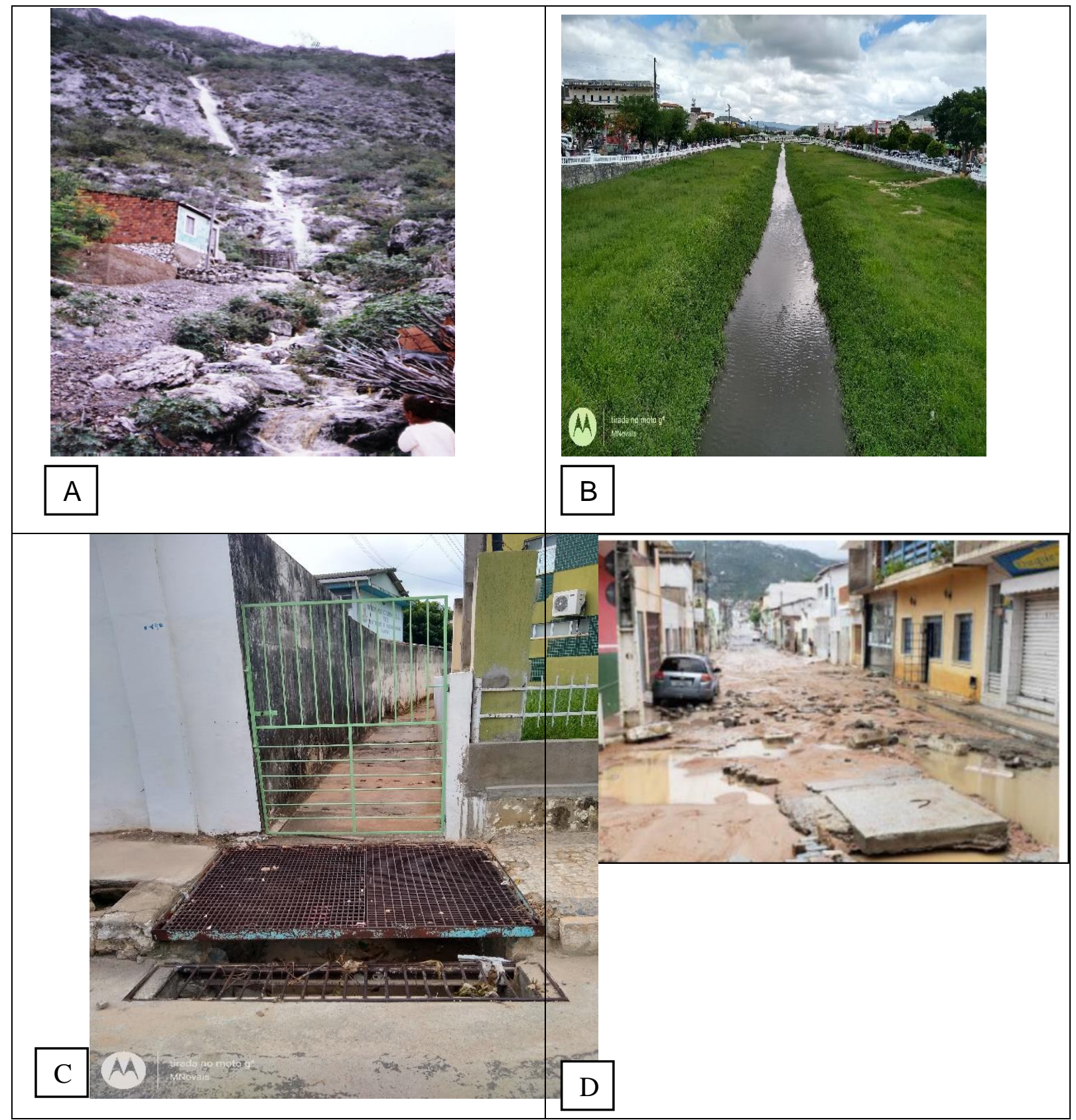

Fonte: NOVAIS,2009; https://www.bahianoticias.com.br/ 
Devido esse evento de chuva intensa e concentrada do dia 09/12 associado as características da área urbana de Jacobina, tais como: geologia/geomorfologia ( vale estreito, alta declividade e afloramentos rochosos nas vertentes), pouca vegetação e presença de diversos drenagens nas encostas, impermeabilização do solo, expansão da malha urbana para áreas de encostas, deficiência no sistema de drenagem pluvial, ausência de um sistema de tratamento e coleta de esgoto, que são lançados in loco nos rios urbanos e a retificação dos principais rios que drenam a cidade (rio ItapicuruMirim e Ouro), favoreceram o fluxo rápido da água pluvial e uma alta energia cinética que danificou ruas pavimentadas por asfaltos e paralelepípedos, e alagou áreas rebaixadas do relevo urbano (Figura 06 - a); b); c) e d)). Dado as características (intensidade e duração) do evento hidrometeorológico foi definido no FIDE como enxurrada (flash flood).

Segundo site local Augusto Urgente (https://www.augustourgente.com.br/) e o registrado no FIDE, foram de $120 \mathrm{~mm}$ a $125 \mathrm{~mm}$ de chuva intensa no intervalo de 2 horas. No entanto, os dados verificados das estações pluviométricas/meteorológica (INMET/INEMA) da área urbana não corroboram com este valor.

No site do Jornal da Chapada de 10/12/2018, esse evento resultou em danos humanos, materiais e prejuízos, afetando principalmente os moradores das áreas de risco e de maior vulnerabilidade física, econômica e social, (Figura 7).

Figura 7 - Retirada de moradores vulneráveis das áreas de risco

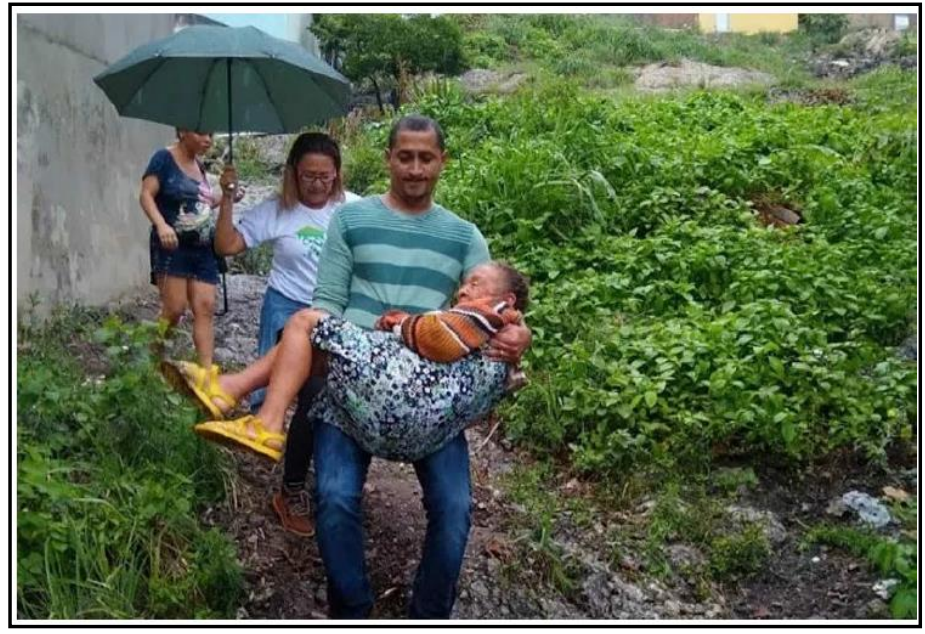

Fonte: Jornal da Chapada, 10/12/2018 
As chuvas provocaram danos em moradias (desabamento total ou parcial), instalações públicas (escolas e unidade de saúde) que estão situadas principalmente áreas suscetíveis as ameaças (perigos) naturais.

O desastre resultou em decreto municipal de situação de emergência através do processo $N^{\circ} 59051.006316 / 2018-90$ de 11/12/2018. Foi registrado 1 enfermo que contraiu leptospirose, 57 pessoas foram atingidas diretamente, principalmente as mais vulneráveis do ponto de vista socioeconômico, em função dos desabamentos e alagamentos de suas moradias, ficando desabrigadas e desalojadas e 800 pessoas foram afetadas com alterações em sua rotina, através da perda de dias de trabalho, problemas de acesso às escolas e creches (FIDE, 2018). Tabela 2.

Tabela 2 - Danos Humanos

\begin{tabular}{l|c}
\hline Discriminação & Quantidade \\
\hline Enfermos & 1 \\
\hline Desabrigados & 22 \\
\hline Desalojados & 35 \\
\hline Outros Afetados & 800 \\
\hline Total dos afetados & 858 \\
\hline
\end{tabular}

Fonte: FIDE, 2018. Elaborado pelo autor

Quanto aos danos materiais, o município teve 130 moradias danificadas e 8 totalmente destruídas, 1 uma instalação de saúde e 4 unidades de ensino danificadas, além das instalações das secretarias de Agricultura e Finanças que tiveram seu funcionamento comprometido em virtude dos alagamentos e $10.000 \mathrm{~m}^{2}$ de pavimentação danificados ou destruídos, no valor $\mathrm{R} \$ 1.875 .000,00$, que corresponde a 13,1\% da receita liquidas mensal do município ( $\mathrm{R} \$ 14.253 .621,82)$, já os prejuízos econômicos público foi no valor de $\mathrm{R} \$ 333.000,00$ (FIDE, 2018).

As características geológica/geomorfológica da paisagem, o processo de urbanização e crescimento da cidade para áreas suscetíveis (vales e vertentes) associada a vulnerabilidade da população constitui-se fatores determinantes na definição de áreas de risco na sede urbana de Jacobina (NOVAIS, 2009; CPRM, 2014) 
(Figura 8). Segundo Ministério das Cidades/Instituto de Pesquisas Tecnológicas (IPT) os locais passíveis de ser atingidos por fenômenos ou processos naturais e/ou induzidos que causem transtornos e efeitos adversos a população são definidos como áreas de risco.

Figura 8 - Confluência do rio Itapicuru-Mirim e rio do Ouro, com intensa ocupação nas margens e em vertentes fortemente inclinadas

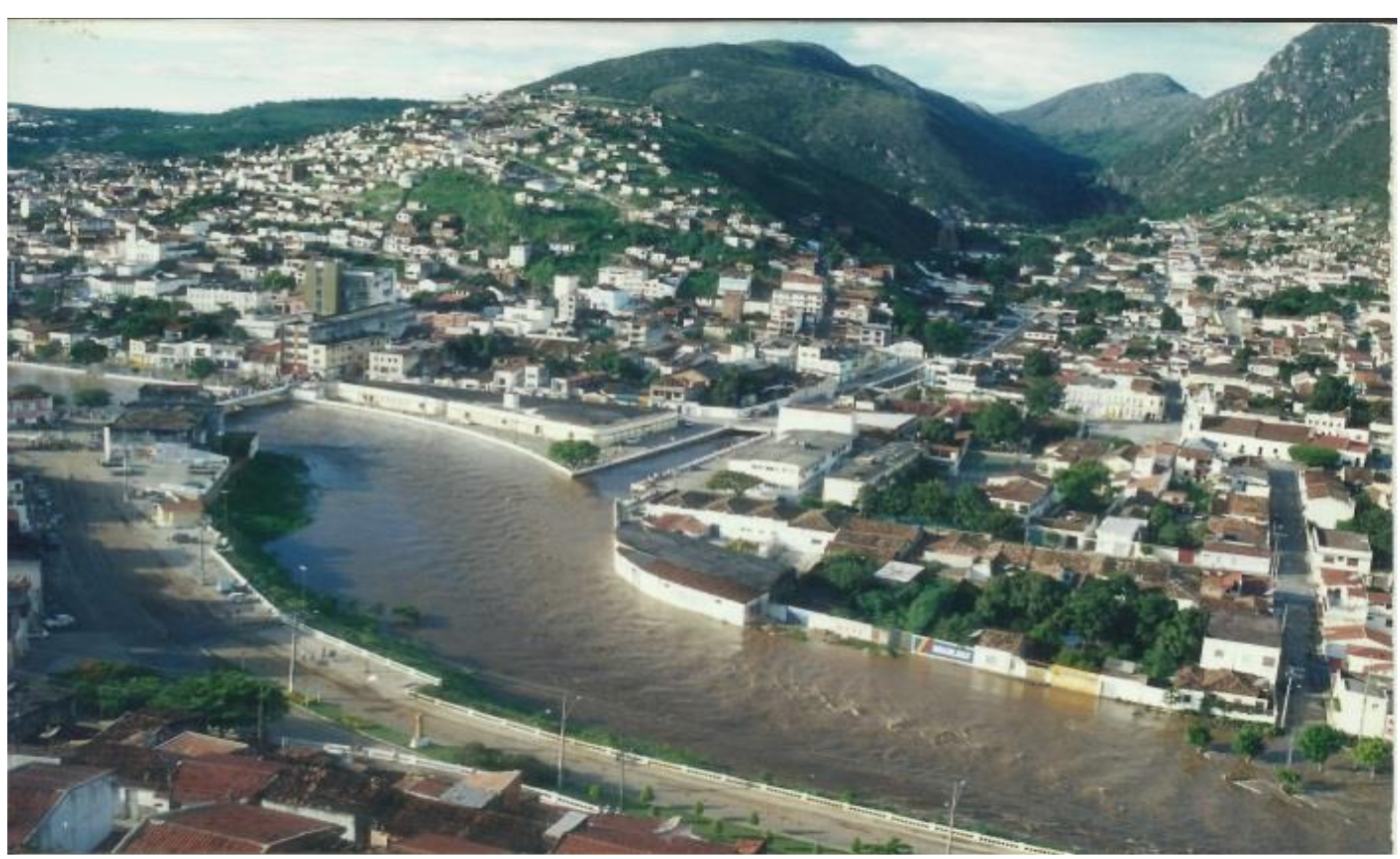

Fonte: CPRM, 2014

Após desastres de 2011 e 2014 em Jacobina, foi realizado pelo Serviço Geológico do Brasil - CPRM a delimitação de áreas de Alto e Muito Alto Risco a Enchentes, Inundações e Movimentos de Massa (Figura 9).

Esses resultados foram cruzados com os dados de Cobertura e Uso da Terra do Ministério de Meio Ambiente (2002) e dos setores censitários (IBGE, 2010), onde foram sobrepostos e resultando em Carta sujeita à Enchentes e Inundações da área urbana de Jacobina na escala de apresentação de 1: 1000 (Figura 10). 
Figura 9 - Delimitação das áreas de alto e muito alto risco de enchente e inundação Jacobina - BA

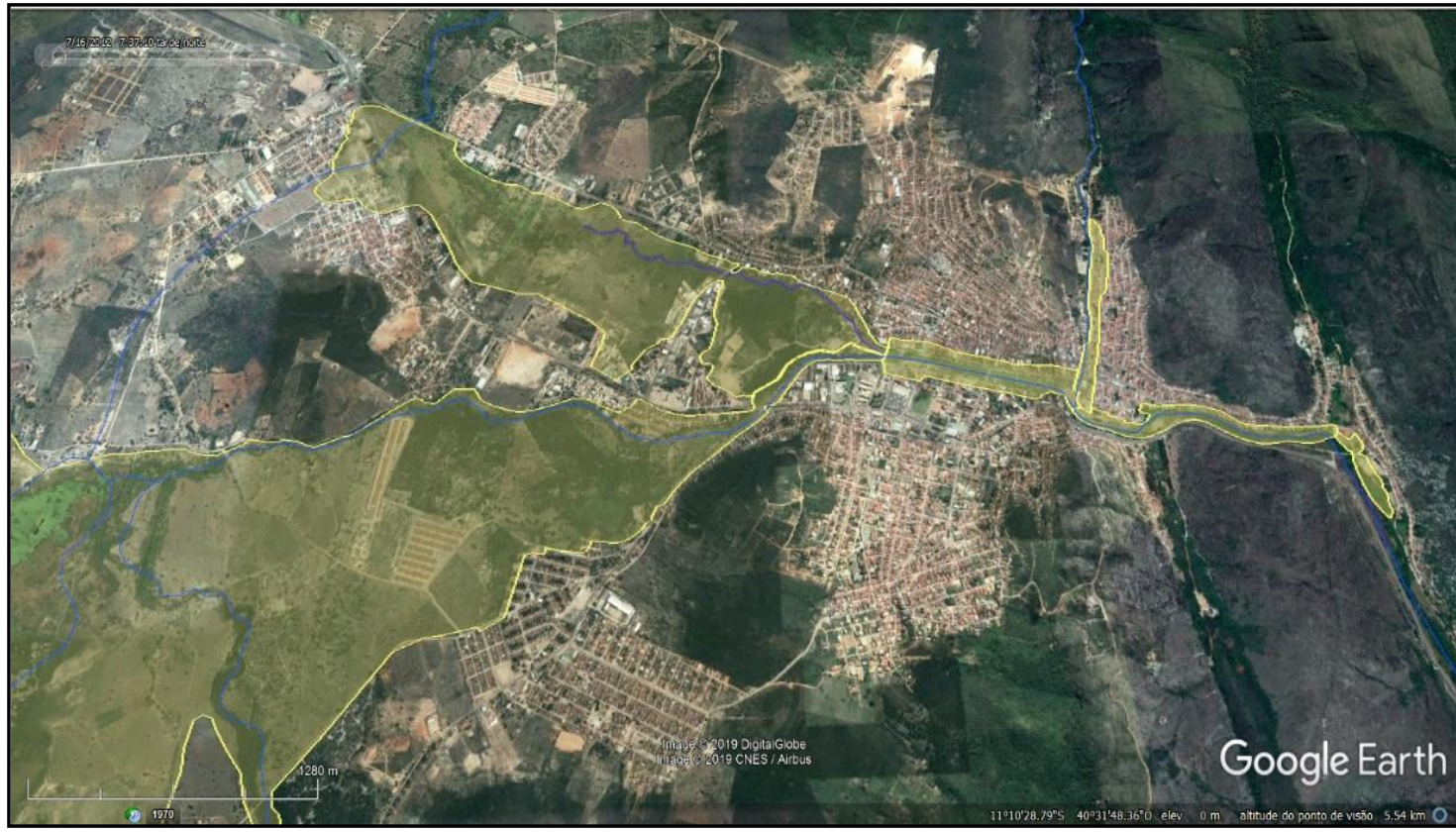

Fonte: CPRM, 2014

Figura 10 - Áreas de Risco de Enchentes e Inundações - Área Urbana de Jacobina - BA

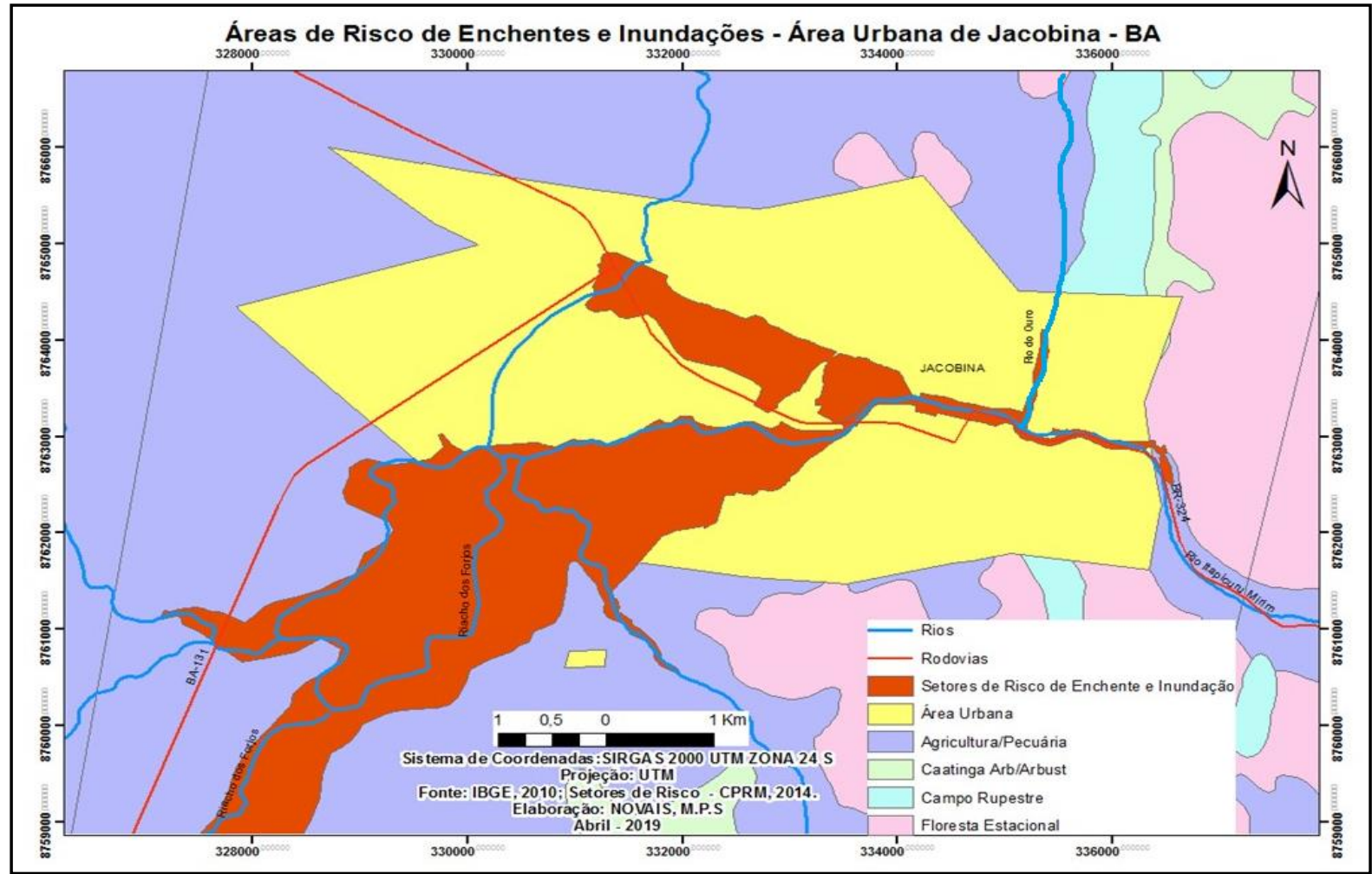

Fonte: IBGE (2010); CPRM (2014) 


\section{CONCLUSÕES}

Neste estudo foi apresentada uma análise do desastre hidrológico (enxurrada) ocorrida na cidade de Jacobina que esteve associada as precipitações intensas ocorridas ao longo do mês de dezembro de 2018, provocando danos (humanos e materiais) e prejuízos para população, afetando as pessoas de maior vulnerabilidade e que ocupam as áreas de risco.

A análise realizada em relação ao fenômeno atmosférico, a partir dos boletins meteorológicos, cartas sinóticas e imagens de satélite, e consulta aos dados de precipitação, demonstram que a maior precipitação máxima diária (24h) de 82,2 mm ocorreu no dia 09/12/2018, associada a atuação da Zona de Convergência do Atlântico Sul - ZCAS, com um cavado em níveis médios e altos e a presença de Vórtice Ciclônico de Altos Níveis - VCAN, que manteve a nebulosidade e instabilidade na região Nordeste naquele período.

A observação da característica geomorfológica da paisagem urbana de Jacobina, com a presença de ocupações em vales encaixados e vertentes de declividade forte, além das intervenções antrópicas através da canalização de trechos urbanos dos rios Rio Itapicuru-Mirim e Rio do Ouro são fatores que potencializam os efeitos dos eventos extremos de chuva e que podem resultar no aumento das áreas de risco, conforme verificado na setorização da CPRM (2014), com maiores danos e prejuízos, principalmente para população vulnerável socioeconomicamente e que ocupam essas áreas.

Esses condicionantes naturais e sociais da paisagem urbana de Jacobina se revelam preocupante, tendo em vista um cenário de mudanças climáticas que aumentam a ocorrência de eventos extremos de precipitação e o aumento da urbanização com ocupações na planície de inundação do Rio Itapicuru-Mirim e das vertentes de declividade elevada, chegando em determinadas situações as áreas de topo. 
Algumas sugestões podem ser apontadas no sentido da redução de risco de desastres em Jacobina, tais como:

a) Realizar ações de orientação, fiscalização e controle no processo de ocupação do espaço urbano, principalmente em áreas de encostas e taludes de corte;

b) Implementar de programas de educação voltados a redução de riscos desastres e princípios de proteção e defesa civil;

c) Elaborar e implementar o Plano Municipal de Drenagem Urbana e o Plano Municipal de Proteção e Defesa Civil;

d) Implementar sistema de alerta para as áreas de risco, através de meios de veiculação pública (mídia, sirenes, celulares), permitindo a remoção eficaz dos moradores, em caso de alertas de chuvas intensas ou contínuas, enviado pelo Centro Nacional de Monitoramento e Alertas de Desastres Naturais - CEMADEN;

e) Mapear a vulnerabilidade das famílias das áreas de risco e estabelecer medidas de enfrentamento e preparação a riscos de desastres;

f) Implantar no município uma gestão de risco de desastres e construir soluções resilientes com base no cruzamento da visão técnica, comunitária e jurídica.

Os resultados obtidos nesta pesquisa demonstram a necessidade de se realizar investigações com maior nível detalhamento do problema em questão, a partir de aspectos como: a identificação, caracterização e detalhamento desastres que afetam a cidade Jacobina ; identificação dos impactos sociais dos desastres com métodos abrangentes; análise das vulnerabilidades do território e da família, e a percepção da população principalmente a afetada diretamente pelos desastres.

\section{REFERÊNCIAS}

BAHIA NOTÍCIAS. Jacobina: chuva causa alagamentos em ruas, casa desabou após temporal. Disponível em: https://www.bahianoticias.com.br/municipios/noticia/15323-jacobina-chuva-causaalagamentos-em-ruas-casa-desabou-apos-temporal.html Acesso em 05 de janeiro de 2019.

BANCO MUNDIAL. Entendendo o Risco Brasil . Belo Horizonte: (URBR), 2012 
BENNETT, M. R., DOYLE, P., L, J. G; PROSSER, C. D. (eds). Geology on your Doorstep. The Role of Urban Geology in Earth Heritage Conservation. $x+$, 1996, 270 pp. London, Bath: Geological Society of London.

BLAIKIE, P.; CANNON, T.; DAVIS, I. \& WISNER, B., 1996. Vulnerabilidad: el Entorno Social, Político y Económico de los Desastres. Colombia: Tercer Mundo Editores.

BRASIL. Ministério das Cidades / Instituto de Pesquisas Tecnológicas (IPT) Mapeamento de Riscos em Encostas e Margem de Rios . CARVALHO, Celso S., MACEDO, Eduardo. S. de, OGURA, Agostinho T. (Orgs.). Brasília: Ministério das Cidades; Instituto de Pesquisas Tecnológicas - IPT, 2007. 176 p. Disponível em:<http://www.cidades.gov.br/images/stories/ArquivosSNPU/Biblioteca/PrevencaoEr radicacao/Livro_Mapeamento_Enconstas_Margens.pdf>. Acesso em: 16 jan. 2016.

BRASIL. Serviço Geológico do Brasil - CPRM. Ação Emergencial para Delimitação de Àreas em Alto e Muito Alto Risco a Enchentes, Inundações e Movimentos de Massa, Jacobina - $\quad$ BA, 2014. Disponível em: http://rigeo.cprm.gov.br/xmlui/handle/doc/18893?show=full Acesso em: 05 de janeiro, 2019.

CARVALHO, L.M. V. de; JONES, C. Zona de Convergência do Atlântico Sul. - In: CAVALCANTI, I. F. de A.[et.al.] org. Tempo e Clima no Brasil. - São Paulo: Oficina de Texto, 2009.

CASTRO, A. L. C. de. SECRETARIA NACIONAL DE DEFESA CIVIL. Glossário de Defesa

Civil Estudos de Riscos e Medicina de Desastres, 5ª ed. - Brasilia: 1998.

CEPED/UFSC. Universidade Federal de Santa Catarina. Centro Universitário de Estudos e Pesquisas sobre Desastres. Atlas brasileiro de desastres naturais 1991 a 2010: volume Bahia. $2^{a}$ versão revisada e ampliada. Centro Universitário de Estudos e Pesquisas sobre Desastres. Florianópolis: CEPED UFSC, 2013. Florianópolis, 2013.Disponível em: http://150.162.127.14:8080/atlas/atlas.html. Acesso em: 12 jun.2016.

CÉSAR, J. R. de A.; ALVES, C. R. Etude de la mise em securité et de la rehabilitation des mines d'or de Jacobina (Bahia - Brasil). Ales, France: Centre d'Études Supérieures pour la Sécurité et l'Environnement Miniers, 2001

EM-DAT. The OFDA/CRED International Disaster Database, 2009. Disponível em: www. em-dat.net. Acesso: 16 jan.2016.

IBGE - Instituto Brasileiro de Geografia e Estatística. “Cidades: Estimativa da população 2018". Disponível em http;//www.ibge.gov.br. Acesso em dez. 2018 
IBGE - Instituto Brasileiro de Geografia e Estatística. Pesquisa Nacional de Saneamento Básico 2008. - Rio de Janeiro: IBGE, 2010. Disponível em http;//www.ibge.gov.br. Acesso em dez. 2018.

JORNAL DA CHAPADA. Chuvas torrenciais causam prejuízos e preocupação a moradores de Jacobina. Disponível em: https://jornaldachapada.com.br/2018/12/10/chapada-chuvas-torrenciais-causamprejuizos-e-preocupacao-a-moradores-de-jacobina/, Acesso em 05 de janeiro de 2019.

PREFEITURA DE JACOBINA. Formulário de Informações de Desastres - FIDE 2018.

KOBIYAMA, M. (Org.). Prevenção de desastres naturais: conceitos básicos. Curitiba: Ed. Organic Trading, 2005. 109p.

MARENGO, J. A. Como as pesquisas das universidades podem ajudar na prevenção de desastres naturais. 2015. Disponível em: https://www.kas.de/c/document_library/get_file?uuid=c1d85c82-b733-3c9e-e270e1d2d7a00916\&groupld=252038. Acesso em: 15.jan.2018.

MIGUEZ, M.G; DI GREGORIO, L. T.; VERÓL, A.P. Gestão de Riscos e Desastres Hidrológicos. - Rio de Janeiro: Elsevier, 2018.

NOVAIS, M.P.S. Desastres ocorridos na bacia Hidrográfica do Rio Itapicuru Bahia, no período de 1991 - 2016. In: $2^{a}$ Seminário Internacional de Proteção e Defesa Civil, 2018, Santa Catarina. Pôster. Santa Catarina: Defesa Civil Santa Catarina, 2018.

NOVAIS, M.P.S.. Aspectos da Apropriação e Ocupação do Espaço na Microbacia rio do Ouro, Jacobina - Bahia e suas Repercussões Socioambientais. 2009. Dissertação (Mestrado em Geografia) Instituto de Geociências da Universidade Federal da Bahia, Salvador - BA, 2009.

OLIVER-SMITH, A. What is a Disaster. In: OLIVER-SMITH, A.; HOFFMAN S. M. (Org.). The Angry Earth: Disaster in Anthropological Perspective. London: Routledge, 1999. p. 1834.

PINHEIRO, C.F. Avaliação Geoambiental do Município de Jacobina - Ba, através das técnicas de geoprocessamento: um suporte ao ordenamento territorial. 2004 Dissertação (Mestrado em Geografia) Instituto de Geociências da Universidade Federal da Bahia, Salvador - BA, 2004.

SANTOS, R. F. Vulnerabilidade Ambiental: Desastres naturais ou fenômenos induzidos? Brasília: Ministério do Meio Ambiente, 2007. 192 p.

TUCCI. C. E. M. Controle de Enchentes. In: TUCCI, C.E.M. (org.). Hidrologia: ciência e aplicação. - 4a ed. - Porto Alegre: Editora da UFRGS/ABEH, 2014. 
TUCCI. C. E. M.. Gestão de Inundações urbanas. [S.I.]: [s.n.], 2005.

UNISDR/ONU. Marco de Ação de Hyogo 2005-2015: Aumento da resiliência das nações e das comunidades frente aos desastres. Disponível em: http://www.integracao.gov.br/cidadesresilientes/pdf/mah_ptb_brochura.pdf. Acesso em: 15 jan. 2016. 